\title{
Atomoxetine Reverses Nicotine Withdrawal-Associated Deficits in Contextual Fear Conditioning
}

\author{
Jennifer A Davis' and Thomas J Gould*,' \\ 'Department of Psychology, Temple University, Philadelphia, PA, USA
}

\begin{abstract}
Recent evidence suggests that the cognitive symptoms of nicotine withdrawal and the cognitive symptoms of attention deficit hyperactivity disorder (ADHD) may share neural correlates. Thus, therapeutics that ameliorate ADHD symptoms may also ameliorate nicotine-withdrawal symptoms. The present research tested this hypothesis in an animal model of nicotine withdrawal-associated cognitive deficits using atomoxetine, a norepinephrine reuptake inhibitor that is approved by the FDA to treat the symptoms of ADHD. C57BL 6 mice were prepared with osmotic minipumps that administered $6.3 \mathrm{mg} / \mathrm{kg} /$ day of nicotine or saline, and the minipumps were removed after 12 days of continuous treatment. Twenty-four hours later, mice were trained in delay fear conditioning using two paired presentations of an auditory conditioned stimulus (CS) with a footshock unconditioned stimulus. Testing for freezing in response to the training context and for freezing in response to the CS occurred the next day. Nicotine-withdrawn mice and their saline-treated counterparts received either saline or atomoxetine before training and the context test. Consistent with previous research, the results indicate that mice withdrawn from chronic nicotine demonstrated lower levels of contextual fear conditioning than mice that were not withdrawn from chronic nicotine. Atomoxetine dose-dependently reversed the deficit, suggesting that nicotine withdrawal may be associated with changes in noradrenergic function, acetycholinergic function, and/or with changes in cell signaling cascades that are activated by both nicotine and norepinephrine. These data suggest that atomoxetine may be efficacious for treating nicotine withdrawalassociated cognitive deficits that promote relapse in abstinent smokers.

Neuropsychopharmacology (2007) 32, 201 I-2019; doi: I0.1038/sj.npp. I30I315; published online 17 January 2007
\end{abstract}

Keywords: atomoxetine; nicotine withdrawal; fear conditioning; addiction; norepinephrine; smoking cessation

\section{INTRODUCTION}

Nicotine addiction is a complex disorder characterized by alterations in behavior and neural function that are just beginning to be understood (Hyman and Malenka, 2001; Picciotto and Corrigall, 2002; Watkins et al, 2000). Although the health risks of nicotine use are well known, 46 million adults in the United States are chronic smokers (Center for Disease Control, 2004). Dependence on tobacco and high rates of relapse may result from the aversive symptoms associated with nicotine withdrawal (Kenny and Markou, 2001); withdrawal from chronic nicotine results in a variety of somatic and affective symptoms in humans, including insomnia, increased appetite, anxiety, and difficulty in concentrating (Hughes et al, 1991; Snyder et al, 1989). The National Institute on Drug Abuse (NIDA, 2004) estimates that, among smokers who attempt to quit each year, less than $6 \%$ are successful in abstaining for a month. The success rates for individuals who seek help through

*Correspondence: Dr TJ Gould, Department of Psychology, Temple university, Weiss Hall, Philadelphia, PA 19122, USA, Tel: + I 215204 7495, Fax: + I 215204 5539, E-mail: tgould@temple.edu

Received 25 July 2006; revised 16 November 2006; accepted 17 November 2006 medication are better; current first-line pharmacological smoking cessation treatments include nicotine replacement (ie nicotine gum, the nicotine lozenge, nicotine patches, and nicotine inhalers), the administration of bupropion, an inhibitor of dopamine and norepinephrine transporters (for a review see Warner and Shoaib, 2005), and the administration of varenicline, a partial agonist of $\alpha 4 \beta 2$ nicotinic receptors (nAChRs; for a review see Foulds, 2006). Although these medications can double the smoking cessation rates relative to placebo (Fiore et al, 2000), only a fraction of treated smokers are able to quit and maintain abstinence (Lerman et al, 2005). Thus, preclinical research to identify novel biological targets for more efficacious treatments is urgently needed.

Nicotine withdrawal symptoms represent an important target for nicotine-dependence medication development. These symptoms are diverse, and expression of these symptoms may vary with environmental and genetic factors (Bergen and Caporaso, 1999; Rende et al, 2005). One frequently reported withdrawal symptom is disrupted cognitive processes (for a reviews see Baker et al, 2004; Jarvis, 2004). In smokers, nicotine abstinence is associated with deficits in concentration (Hendricks et al, 2006), sustained attention (Hendricks et al, 2006), digit recall (Snyder et al, 1989), paired associate learning (Kleinman 
et al, 1973), and with increases in reaction time in a twoletter search task (Bell et al, 1999). Importantly, increases in self-reported cognitive deficits following smoking cessation predict the likelihood of relapse (Rukstalis et al, 2005).

Despite support for the clinical importance of nicotine abstinence-induced cognitive deficits, few studies have investigated the effects of withdrawal from nicotine on learning in animal models. Work from our lab examined the effects of acute systemic nicotine, chronic systemic nicotine, and withdrawal from chronic systemic nicotine on fear conditioning in C57BL/6 mice (for review see Gould, 2006). The use of fear conditioning to examine the effects of nicotine on learning offers advantages over other tasks. First, the task is rapidly acquired and can, therefore, be utilized to examine the effects of nicotine and nicotine withdrawal on acquisition (ie learning). Second, the task involves two types of learning that recruit different brain regions. Specifically, mice are trained using two paired, coterminating presentations of a discrete auditory conditioned stimulus (CS) with a footshock unconditioned stimulus (US) (Gould and Higgins, 2003; Gould and Wehner, 1999; Logue et al, 1997; Owen et al, 1997). Two associations are formed as a result of training: a hippocampus-dependent association between the context in which training occurred and the US, and a hippocampusindependent association between the auditory CS and the US (Fanselow et al, 1994; Logue et al, 1997; Phillips and Ledoux, 1992). Fear conditioning can be used, then, to assess if the effects of nicotine are specific to one type of learning or if they generalize across types of learning. Such data can provide information that will aid in understanding the behavioral and neural processes that underlie nicotine addiction, thereby leading to novel therapeutics.

The results of our research (Davis and Gould, 2006; Davis et al, 2005, 2006; Gould, 2003; Gould et al, 2004; Gould and Higgins, 2003; Gould and Lommock, 2003; Gould and Wehner, 1999) and the research of others (Wehner et al, 2004) indicate that acute nicotine dose dependently enhances contextual fear conditioning. In mice, chronic administration of a dose of nicotine that produces plasma nicotine levels that are similar to the acute dose of nicotine that enhances contextual fear conditioning has no effect on the task, suggesting the development of tolerance. Withdrawal from this dose of nicotine is associated with impaired contextual fear conditioning (Davis et al, 2005). This withdrawal-associated deficit did not generalize to conditioning to the auditory CS, suggesting that the deficit is not due to general alterations in arousal or fear intensity.

With the development and validation of this, an animal model for studying nicotine withdrawal-associated deficits in learning, it is possible to screen potential ameliorative agents for the treatment of nicotine withdrawal-associated deficits in cognitive processes. Previous research has demonstrated that administration of an acute dose of nicotine reverses nicotine withdrawal-associated deficits in contextual fear conditioning (Davis et al, 2005); this may model the ability of nicotine replacement to aid in reducing nicotine withdrawal symptoms. The present research targeted a novel non-nicotine therapeutic agent for the treatment of nicotine withdrawal-related deficits in cognitive-related processes.
Atomoxetine, a norepinephrine-reuptake inhibitor approved by the FDA to treat attention deficit hyperactivity disorder (ADHD) (Kratochvil et al, 2003), increases the amount of synaptic norepinephrine and, to a lesser extent, dopamine and serotonin, by inhibiting the reuptake of these neurotransmitters (Swanson et al, 2006). In addition, a recent study (Tzavara et al, 2006) suggests that atomoxetine indirectly increases acetylcholine levels via activation of $\alpha-1$ norepinephrine receptors and/or activation of $\mathrm{D} 1$ dopamine receptors. ADHD is characterized by cognitive symptoms that are similar to those seen during nicotine withdrawal. Specifically, individuals with ADHD experience deficits in both selective and sustained attention, motivation, and working memory (see Beane and Marrocco (2004) for a review). These symptoms have been attributed to alterations in the acetylcholinergic and noradrenergic systems (for a review see Beane and Marrocco, 2004).

Recent research indicates that individuals with ADHD are more likely to smoke (Lambert and Hartsough, 1998; Pomerleau et al, 2003) and suffer more severe withdrawal symptoms following smoking cessation than individuals who do not have the disorder (Pomerleau et al, 2003). Furthermore, Conners et al (1996) demonstrated that acute nicotine reverses some of the attentional deficits seen in ADHD, and subthreshold symptoms of ADHD (eg concentration deficits, impulsivity) are associated with nicotine dependence and promote 'self-medication smoking' (Lerman et al, 2001). Increases in such ADHD symptoms following smoking cessation are associated with a greater risk of relapse (Rukstalis et al, 2005). These data suggest that ADHD and nicotine addiction may be comorbid and that nicotine withdrawal symptoms and ADHD may share similar neural correlates. In addition, these converging lines of evidence support the hypothesis that a drug, such as atomoxetine, that is efficacious for treating ADHD symptoms may also be efficacious for treating nicotine withdrawal-associated deficits in cognition that promote relapse. Therefore, the present study examined if atomoxetine would reverse nicotine withdrawal-associated deficits in contextual fear conditioning in C57BL/6 mice.

\section{METHODS}

\section{Subjects}

Eight- to twelve-week-old, male C57BL/6 mice ( $n=8-13$ per group) were purchased from the Jackson Laboratories. Mice were housed in groups of four and provided with ad libitum access to food and water. The colony room was maintained on a $12 \mathrm{~h}$ light $/ 12 \mathrm{~h}$ dark schedule (lights on at 07:00), and all behavioral, surgical, and pharmacological procedures occurred between the hours of 08:00 and 18:00.

\section{Drugs and Administration}

Mice were prepared with mini osmotic pumps (Alzet, model 1002, Durect Co., Cupertino, CA) that administered saline or $6.3 \mathrm{mg} / \mathrm{kg} /$ day of nicotine bitartrate (Sigma, St Louis, MO; dose reported as freebase) at a rate of $0.25 \mu \mathrm{l} / \mathrm{h}$. Pumps were removed on day $12,24 \mathrm{~h}$ before the mice were trained in delay fear conditioning. The dose and duration of nicotine administration were selected based on data from a previous 
study (Davis et al, 2005), indicating that mice withdrawn from administration of $6.3 \mathrm{mg} / \mathrm{kg} /$ day of nicotine for 12 days were impaired in contextual fear conditioning. In addition, this dose of chronic nicotine produced plasma nicotine levels similar to those seen in smokers (Benowitz et al, 1989; Henningfield and Keenan, 1993). All mice received an acute intraperitoneal injection of either saline or atomoxetine (Sigma; 0.2 or $2.0 \mathrm{mg} / \mathrm{kg}$ ) $20 \mathrm{~min}$ before training and testing for freezing in response to the context in experiments 1 and 2. In experiment 3 , mice withdrawn from chronic nicotine received saline or $2.0 \mathrm{mg} / \mathrm{kg}$ of atomoxetine before training or before testing for freezing in response to the context. For all experiments, atomoxetine was not administered before testing for freezing in response to the CS, because previous research (Swanson et al, 2006) indicates that rat brain concentrations of norepinephrine remain elevated $4 \mathrm{~h}$ after administration of a dose of atomoxetine that is similar to our effective dose of the drug. The doses of atomoxetine used for the present studies were selected based on a previous study from our lab (Gould et al, 2005). Furthermore, similar doses of atomoxetine have been shown to be effective in ameliorating ADHD in animal models (Blondeau and Dellu-Hagedorn, 2006; Moran-Gates et al, 2005). Drugs were dissolved in saline and acutely administered at an injection volume of $0.01 \mathrm{ml} / \mathrm{g}$ of bodyweight.

\section{Surgical Procedures}

Mini osmotic pumps were implanted subcutaneously via an incision in the back of each mouse, as described in Davis et al (2005). Surgical procedures were conducted under sterile conditions, and mice were anesthetized during the surgery using isoflurane.

\section{Apparatus}

Training and testing for freezing in response to the training context occurred in four identical conditioning chambers $(17.78 \times 19.05 \times 38.10 \mathrm{~cm})$ that were housed in sound attenuating boxes (MED Associates, St Albans, VT). The training chambers were constructed of Plexiglas walls in the front and back and stainless-steel sides. Each chamber floor was comprised of 18 metal rods spaced $0.6 \mathrm{~cm}$ apart and connected to a shock scrambler. Background noise ( $69 \mathrm{~dB})$ and air exchange was provided by fans located at the back of each box, and speakers for delivering the CS were mounted on the right wall of each box. Stimulus administration was controlled by an IBM-PC running MED-PC software.

Testing for freezing in response to the CS occurred in separate conditioning chambers housed in sound attenuating boxes that differed from the training chambers in size $(20.32 \times 22.86 \times 17.78 \mathrm{~cm})$, construction (clear, Plexiglas walls on the front, back, and sides, and an opaque plastic floor), and location. In addition, a novel olfactory cue (vanilla extract) was added to further alter the context. A speaker for delivering the CS was mounted on the left wall of the conditioning box.

\section{Behavioral Procedures}

Mice were trained using two coterminating white noise CS $(30 \mathrm{~s}, 85 \mathrm{~dB})$-footshock US $(2 \mathrm{~s}, 5.7 \mathrm{~mA})$ pairings. Training sessions were $5.5 \mathrm{~min}$ in duration: baseline freezing was evaluated during the first $120 \mathrm{~s}$ before the first CS-US presentation, immediate freezing was evaluated during the $120 \mathrm{~s}$ intertrial interval (ITI), and the training session ended with a 30 -s period during which behavior was not evaluated. Twenty-four hours after training, freezing in response to the training context was assessed for $5 \mathrm{~min}$. Generalized freezing (pre-CS) and freezing in response to the CS were evaluated $1 \mathrm{~h}$ later over $6 \mathrm{~min}$ in altered context chambers; pre-CS freezing was assessed during the first $180 \mathrm{~s}$, and freezing in response to the CS was assessed for the next $180 \mathrm{~s}$.

Freezing, the absence of movement except for respiration, was used as a behavioral measure of the associations between the context and the US and the CS and the US. As in previous research (Davis and Gould, 2006; Davis et al, 2005, 2006; Gould, 2003; Gould et al, 2004; Gould and Higgins, 2003; Gould and Lommock, 2003; Gould and Wehner, 1999), a time-sampling procedure in which the freezing behavior of each mouse was assessed by experimenters who have shown inter-rater reliability $>90 \%$ for $1 \mathrm{~s}$ every $10 \mathrm{~s}$ was employed to record freezing behavior during training and testing. Experimenters who scored the behavior were blind to the condition of each animal in order to prevent observer bias.

\section{Statistical Analyses}

Data for the first experiment were analyzed using 2 (withdrawal treatment group) $\times 2$ (saline or $2.0 \mathrm{mg} / \mathrm{kg}$ atomoxetine) ANOVAs. Post hoc, Tukey-adjusted contrasts were performed to determine differences between groups. Data for the second and third experiments were analyzed using one-way ANOVAs, and post hoc comparisons were carried out using Tukey-adjusted contrasts.

\section{RESULTS}

The effects of withdrawal from chronic nicotine and atomoxetine administration on baseline, immediate, contextual, pre-CS, and CS freezing were examined (see Figure 1). A $2 \times 2$ ANOVA revealed a main effect of saline/atomoxetine treatment group on freezing in response to the training context at testing $(F(1,34)=15.70, p<0.05)$ and a significant interaction between the withdrawal treatment variable and the saline/atomoxetine treatment variable $(F(1,34)=9.59, p<0.05)$. Tukey HSD analyses indicated that mice withdrawn from chronic nicotine $(6.3 \mathrm{mg} / \mathrm{kg} /$ day for 12 days $)$ that received saline at training and context test $(n=10)$ were impaired in contextual fear conditioning compared to all other groups $(t(34)=2.74$, $p<0.05 ; t(34)=3.28, p<0.05 ; t(34)=4.99, p<0.05 v s$ mice withdrawn from chronic saline and treated with acute saline $(n=10)$, mice withdrawn from chronic saline and treated with $2.0 \mathrm{mg} / \mathrm{kg}$ of atomoxetine $(n=9)$, and mice withdrawn from chronic nicotine and treated with $2.0 \mathrm{mg} / \mathrm{kg}$ of atomoxetine $(n=9))$. Thus, administration of $2.0 \mathrm{mg} / \mathrm{kg}$ of atomoxetine reversed the nicotine withdrawal-associated deficit in contextual fear conditioning, because mice withdrawn from chronic nicotine that received atomoxetine demonstrated levels of contextual fear conditioning that were similar to saline-withdrawn mice that received saline 


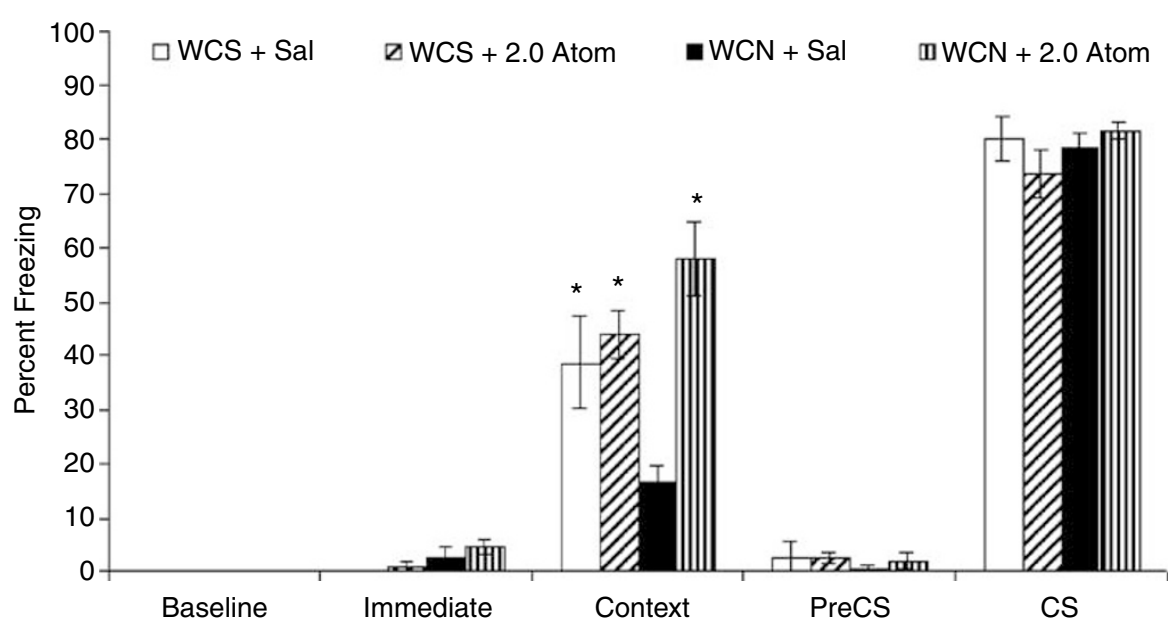

Figure I The effects of withdrawal from chronic nicotine and atomoxetine administration on contextual and auditory fear conditioning were examined. Tukey-adjusted post hoc analyses revealed that mice that were withdrawn from nicotine and received saline before training and testing (WCN + sal) demonstrated significantly lower levels of freezing in response to the context than mice withdrawn from chronic saline that received saline before training and testing (WCS + Sal). Atomoxetine (WCN + 2.0 Atom) administration reversed this deficit. There were no differences among groups in freezing in response to the CS. Nor were there significant pairwise differences between groups in baseline, immediate, or pre-CS freezing. Error bars represent \pm SE from the mean. $* p<0.05$ compared to mice withdrawn from chronic nicotine that received saline before training and testing $(\mathrm{WCN}+$ sal). $n=9-10$ per group.

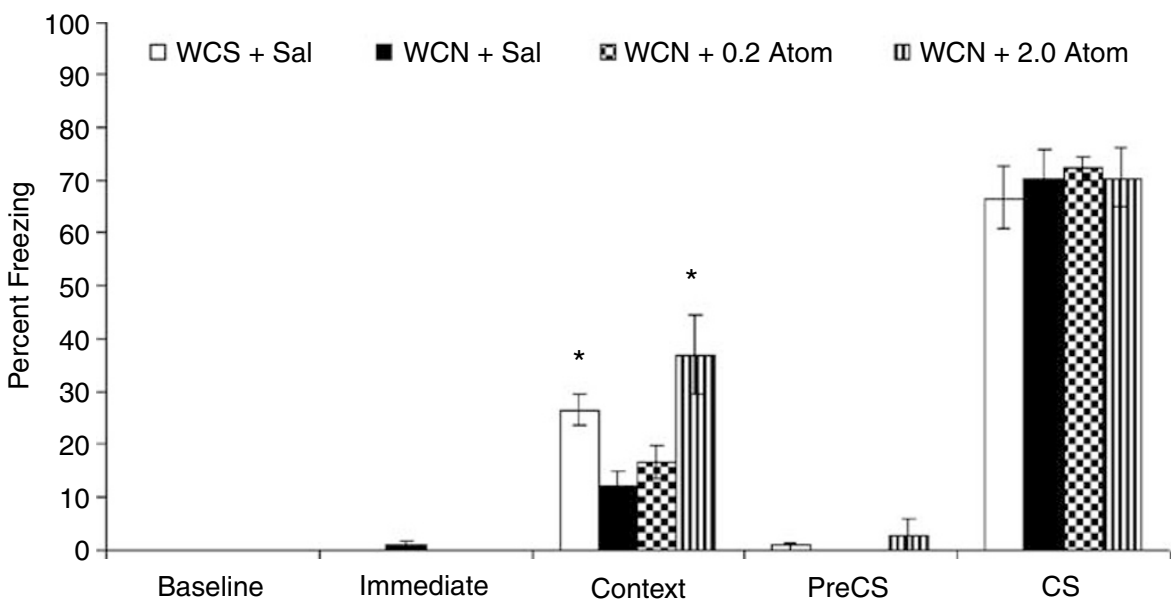

Figure 2 A second experiment was conducted to determine if a lower dose of atomoxetine would reverse nicotine withdrawal-associated deficits in contextual fear conditioning and to replicate our finding with the $2.0 \mathrm{mg} / \mathrm{kg}$ dose of atomoxetine. Tukey-adjusted follow-up comparisons revealed that $2.0 \mathrm{mg} / \mathrm{kg}(\mathrm{WCN}+2.0$ Atom) but not $0.2 \mathrm{mg} / \mathrm{kg}(\mathrm{WCN}+0.2$ Atom) of atomoxetine reversed the nicotine withdrawal-associated deficit in contextual fear conditioning. There were no differences among groups in baseline, immediate, pre-CS, and CS freezing. Error bars represent \pm SE from the mean. * $p<0.05$ compared to mice withdrawn from chronic nicotine that received saline before training and testing (WCN + sal). $n=9-10$ per group.

before training and testing $(p>0.05)$. Mice withdrawn from chronic saline that received atomoxetine also demonstrated levels of contextual fear conditioning that were similar to saline-withdrawn mice that received saline before training and testing $(p>0.05)$.

Multiple $2 \times 2$ ANOVAs were performed to examine the effects of withdrawal from chronic nicotine and atomoxetine administration on baseline, pre-CS, and CS freezing revealed no significant main effects and no significant interactions among the groups ( $p>0.05$ for all comparisons). There was a significant main effect of withdrawal treatment group on immediate freezing $(F(1,34)=6.19$, $p<0.05)$; mice withdrawn from chronic nicotine demonstrated higher levels of immediate freezing than mice withdrawn from chronic saline administration regardless of atomoxetine treatment. Post hoc comparisons between the treatment groups revealed no significant pairwise differences in this measure ( $p>0.05$ for all comparisons).

To determine if a lower dose of atomoxetine would reverse nicotine withdrawal-associated deficits in contextual fear conditioning and to replicate our finding with the $2.0 \mathrm{mg} / \mathrm{kg}$ dose of atomoxetine, a second experiment was conducted (Figure 2). Mice withdrawn from chronic nicotine received an acute injection of saline $(n=9)$, $0.2 \mathrm{mg} / \mathrm{kg}$ of atomoxetine $(n=9)$, or $2.0 \mathrm{mg} / \mathrm{kg}$ of atomoxetine $(n=10)$ before training and testing. As in the first experiment, there was an effect of treatment on freezing in response to the training context at testing $(F(3,37)=6.36$, 


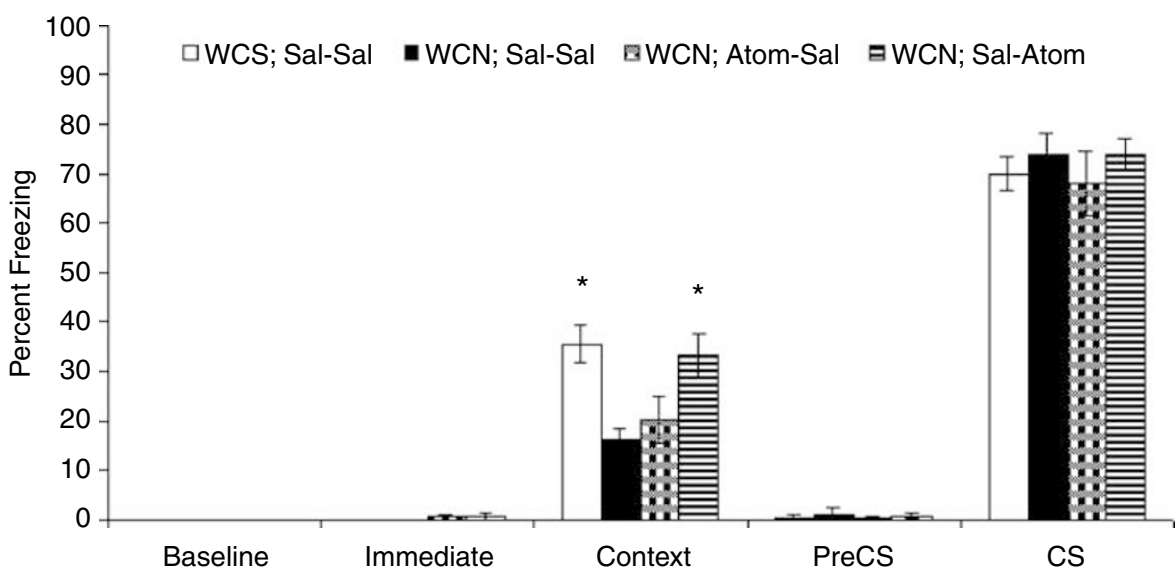

Figure 3 Experiment 3 examined if atomoxetine administration before training only or testing only would reverse nicotine withdrawal-associated deficits in contextual fear conditioning. A one-way ANOVA revealed that there was an effect of treatment. Tukey-adjusted follow-up comparisons indicate that mice withdrawn from chronic nicotine were impaired in contextual fear conditioning (WCN; Sal-Sal) compared to mice withdrawn from chronic saline that received saline at training and testing (WCS; Sal-Sal). Atomoxetine administration prior to testing only (WCN; Sal-Atom) but not training only (WCN; Atom-Sal) reversed this deficit. Error bars represent \pm SE from the mean. $* p<0.05$ compared to mice withdrawn from chronic nicotine that received saline before training and testing. $n=10-13$ per group.

$p<0.05)$. Post hoc comparisons revealed that mice withdrawn from chronic nicotine that received saline at training and testing demonstrated significantly lower levels of contextual fear than mice withdrawn from chronic saline that received saline at training and testing $(n=9)$. Furthermore, the nicotine withdrawal-associated deficit in contextual fear conditioning was reversed by administration of $2.0 \mathrm{mg} / \mathrm{kg}$ of atomoxetine $(t(37)=4.04, p<0.05)$, but not $0.2 \mathrm{mg} / \mathrm{kg}$ of atomoxetine $(p>0.05)$. There were no differences among groups in baseline, immediate, pre-CS, and CS freezing ( $p>0.05$ for all comparisons). This lack of significant differences between groups in freezing in response to the CS, pre-CS freezing, and baseline freezing, suggests that the deficit in contextual fear conditioning in mice withdrawn from chronic nicotine is not due to alterations in general arousal and general freezing behavior.

A third experiment was conducted to examine if atomoxetine $(2.0 \mathrm{mg} / \mathrm{kg})$ administration before training alone or testing alone would reverse the nicotine withdrawal-associated deficit in contextual fear conditioning (Figure 3). One-way ANOVAs revealed that there were no differences among the treatment groups in baseline freezing, immediate freezing, pre-CS freezing, and freezing in response to the CS ( $p>0.05$ for all comparisons). However, there was a significant effect of treatment on contextual fear conditioning $(F(3,41)=5.59, p<0.05)$. Post hoc analyses indicated that mice withdrawn from chronic nicotine that received saline before training and testing $(n=10)$ demonstrated significantly lower levels of contextual fear conditioning than mice withdrawn from chronic saline that received saline before both training and testing $(n=10$; $t(41)=3.29, p<0.05)$. The nicotine withdrawal-associated deficit was reversed when atomoxetine was administered before testing for freezing in response to the training context $(n=12 ; t(41)=2.97, \quad p<0.05)$, but not when atomoxetine was administered before training $(n=13$; $p>0.05)$. In fact, mice withdrawn from chronic nicotine that received atomoxetine before training $(n=13)$ froze significantly less in response to the training context than their saline-treated counterparts $(t(41)=2.79, p<0.05)$.

\section{DISCUSSION}

The present study provides the first evidence that nicotine withdrawal-associated deficits in contextual fear conditioning (Davis et al, 2005) can be reversed by atomoxetine, a norepinephrine reuptake inhibitor used to treat ADHD. More specifically, atomoxetine reverses deficits in contextual fear conditioning when administered before testing but not before training. These results could suggest that the observed nicotine withdrawal-associated impairment is due to a deficit in the retrieval of the association, which is reversed by atomoxetine administration. Alternatively, mice withdrawn from chronic nicotine could be impaired in the acquisition of contextual fear conditioning, and atomoxetine administration could be enhancing retrieval thereby increasing levels of contextual fear conditioning in nicotine withdrawn mice to levels that are comparable to those of controls. A recent study by Murchison and colleagues (2004) suggesting that the norepinephrine promotes retrieval of contextual and spatial memories provides evidence for the latter interpretation.

In order to understand how atomoxetine administration reversed the nicotine withdrawal-associated deficit in contextual fear conditioning, it is necessary to understand how nicotine withdrawal produces its effects on contextual fear conditioning. Although the mechanism(s) through which nicotine withdrawal disrupts contextual fear conditioning remain unknown, a number of possibilities exist; nicotine withdrawal could disrupt contextual fear conditioning by altering $\mathrm{nAChR}$ function, by altering neurotransmitter release, and/or by altering cell signaling cascades that support learning and/or recall of the task. Atomoxetine could ameliorate nicotine withdrawal-associated deficits in contextual fear conditioning by counteracting some or all of these types of changes in neural function.

Chronic nicotine administration is associated with nAChR desensitization (Marks et al, 1983, 1991; Olale et al, 1997; Peng et al, 1993, 1994, 1997; Wooltorton et al, 2003) and with increases in NAChR density (Collins et al, 
1988, 1994; Collins and Marks, 1989; Marks et al, 1983, 1985, 1991, 1992; Nguyen et al, 2003; Pauly et al, 1991, 1996; Peng et al, 1994, 1997; Perry et al, 1999; Whiteaker et al, 1998). These functional changes could lead to alterations in learning-related acetylcholine release, which could contribute to deficits in contextual fear conditioning during nicotine withdrawal. It is possible, then, that atomoxetine counteracted a potential nicotine withdrawal-related alterations in nAChR function and number by increasing acetylcholine levels. In support, atomoxetine dose dependently increases levels of acetylcholine in the hippocampus and the prefrontal cortex via $\alpha 2$ norepinephrine and/or D2 dopamine receptor activation (Tzavara et al, 2006). Further research is necessary to determine if withdrawal-related changes in $n A C h R$ function and number underlie the deficit seen in contextual fear conditioning and to determine if this is one mechanism through which atomoxetine administration reversed this deficit.

Atomoxetine may also reverse nicotine withdrawalrelated deficits in contextual fear conditioning by altering noradrenergic function. Both nicotine administration (see, eg, Azam and McIntosh, 2006; Barik and Wonnacott, 2006; Singer et al, 2004) and atomoxetine administration (Swanson et al, 2006) can increase norepinephrine levels in brain regions that are involved in contextual fear conditioning, including the hippocampus. Alterations in noradrenergic function that may result from chronic nicotine treatment, and withdrawal from chronic nicotine treatment could lead to disrupted contextual fear conditioning during nicotine withdrawal. In support, multiple studies have shown that chronic nicotine treatment is associated with altered noradrenergic function. However, the direction of the functional alterations varies across studies. For example, $\mathrm{Fu}$ and colleagues (1998) demonstrated that nicotine-stimulated norepinephrine release in the hippocampus was reduced following repeated intrahippocampal nicotine infusions. Conversely, Grilli et al (2005) reported that continuous chronic nicotine treatment in vivo was associated with increased nicotine-stimulated norepinephrine release in hippocampal synaptosome preparations. Studies that assessed the effects of nicotine withdrawal on noradrenergic function have also yielded conflicting results. Jacobs et al (2002) demonstrated that nicotine-stimulated norepinephrine release from rat hippocampal slices was decreased in mice treated chronically for 10 days with nicotine via twice daily injections and withdrawn for $14 \mathrm{~h}$ after the last injection. In contrast, Barik and Wonnacott (2006) demonstrated that cholinestimulated norepinephrine release in hippocampal slices was increased 3 days after rats were withdrawn from continuous nicotine administration via osmotic minipumps. Divergent results among studies that examine the effects of chronic nicotine and nicotine withdrawal on noradrenergic function may reflect differences in nicotine dose and administration patterns. In addition, the time of testing after nicotine withdrawal may have contributed to differences in the results; Barik and Wonnacott (2006) examined norepinephrine release 3 days after nicotine was withdrawn, whereas Jacobs et al (2002) examined NE release after $14 \mathrm{~h}$ of nicotine withdrawal. Nonetheless, the possibility that both the disruptive effects of nicotine withdrawal on contextual fear conditioning and the ameliorative effects of atomoxetine involve altered noradrenergic function is an intriguing idea that warrants further attention.

In addition to alterations in cholinergic and noradrenergic function, it is also possible that chronic nicotine administration and nicotine withdrawal alter cell-signaling cascades involved in contextual fear conditioning. Atomoxetine could reverse behavioral deficits that result from such alterations by stimulating those same cell-signaling cascades. For example, extracellular-regulated kinase (ERK) is critically involved in contextual fear conditioning (see Adams and Sweatt (2002) and Sweatt (2004) for reviews), and cAMP response element binding protein (CREB), one of the downstream targets of ERK (Abel and Kandel, 1998; Abel and Lattal, 2001; Athos et al, 2002; Bourtchuladze et al, 1994), is also critically involved in contextual fear conditioning (Athos et al, 2002; Bourtchuladze et al, 1994). Recent research indicates that chronic nicotine administration alters both ERK and CREB activation (Brunzell et al, 2003), and nicotine withdrawal also alters CREB activation (Brunzell et al, 2003; Pandey et al, 2001; Pluzarev and Pandey, 2004). It should be noted, however, that the direction of chronic nicotine and withdrawal from chronic nicotine-related alterations in ERK and CREB activation vary across brain regions and with methods of administration.

Provided that disruptions in ERK, CREB, and/or other second messengers involved in contextual fear conditioning underlie nicotine withdrawal-associated deficits in the task, increased activation of adrenergic receptors via atomoxetine administration could reverse these disruptions. Indeed, activation of $\beta$ adrenergic receptors is critically involved in ERK-dependent LTP in the hippocampus (Thomas et al, 1996; Winder et al, 1999), and $\beta$ adrenergic receptor activation is associated with increased ERK activation (Berkeley and Levey, 2003; Watabe et al, 2000) and CREB activation (Lin et al, 1998; Thonberg et al, 2002). The possibility that nicotine withdrawal and atomoxetine administration during nicotine withdrawal alter contextual fear conditioning via changes in ERK, CREB, and/or other second messengers will require further study.

In summary, the data presented here indicate that atomoxetine reverses nicotine withdrawal-associated deficits in contextual fear conditioning. Although the mechanism(s) through which atomoxetine reverses the nicotine withdrawal-associated deficits in contextual fear conditioning is unknown, these results suggest that atomoxetine might prove useful in aiding in smoking cessation and that clinical investigations are warranted. Clearly, additional research is necessary to understand the factors that contribute to nicotine withdrawal-associated deficits in cognitive processes and to understand how atomoxetine can reverse these deficits. Understanding these processes might lead to the development of more effective treatments for nicotine withdrawal symptoms.

\section{ACKNOWLEDGEMENTS}

We acknowledge grant support from the National Institute on Drug Abuse (DA017949 TG), Temple University (TG), and the National Cancer Institute/National Institute on Drug Abuse Transdisciplinary Tobacco Use Research 
Center Grant (P5084718 PI: Caryn Lerman, PhD). Jennifer A Davis was supported by an NIH/NIDA training grant (T32DA07237).

\section{REFERENCES}

Abel T, Kandel E (1998). Positive and negative regulatory mechanisms that mediate long-term memory storage. Brain Res Rev 26: 360-378.

Abel T, Lattal KM (2001). Molecular mechanisms of memory acquisition, consolidation, and retrieval. Curr Opin Neurobiol 11: 180-187.

Adams JP, Sweatt JD (2002). Molecular psychology: roles for the ERK MAP kinase cascade in memory. Ann Rev Pharmacolog Toxicol 42: 135-163.

Athos J, Impey S, Pineda VV, Chen X, Storm DR (2002). Hippocampal CRE-mediated gene expression is required for contextual memory formation. Nat Neurosc 5: 1119-1120.

Azam L, McIntosh JM (2006). Characterization of nicotinic acetylcholine receptors that modulate nicotine-evoked $\left[{ }^{3} \mathrm{H}\right]$ norepinephrine release from mouse hippocampal synaptosomes. Mol Pharmaco (E-pub ahead of print).

Baker TB, Brandon TH, Chassin L (2004). Motivational influences on cigarette smoking. Ann Rev Psychol 55: 463-491.

Barik J, Wonnacott S (2006). Indirect modulation by $\alpha 7$ nicotine acetylcholine receptors of noradrenaline release in rat hippocampal slices: interaction with glutamate and GABA systems and effect of nicotine withdrawal. Mol Pharmacol 69: 618-628.

Beane M, Marrocco RT (2004). Norepinephrine and acetylcholine mediation of the components of reflexive attention: implications for attention deficit disorders. Prog Neurobiol 74: 167-181.

Bell SL, Taylor RC, Singleton EG, Henningfield JE, Heishman SJ (1999). Smoking after nicotine deprivation enhances cognitive performance and decreases tobacco craving in drug abusers. Nicotine Tobacco Res 1: 45-52.

Benowitz NL, Porchet H, Jacob P (1989). Nicotine dependence and tolerance in ma: pharmakinetic and pharmacodynamic investigations. Prog Brain Res 79: 279-287.

Bergen AW, Caporaso N (1999). Cigarette smoking. J Nat Cancer Inst 91: 1365-1375.

Berkeley JL, Levey AI (2003). Cell-specific extracellular signalregulated kinase activation by multiple $G$ protein-coupled receptor families in the hippocampus. Mol Pharmacol 63: 128-135.

Blondeau C, Dellu-Hagedorn F (2006). Dimensional analysis of ADHD subtypes in rats. Biol Psychiatry [E-pub ahead of print].

Bourtchuladze R, Frengeulli B, Blendy J, Cioffi D, Schutz G, Silva AJ (1994). Deficient long-term memory in mice with a targeted mutation of the cAMP-responsive element-binding protein. Cell 79: $59-68$.

Brunzell DH, Russell DS, Picciotto MR (2003). In vivo nicotine treatment regulates mesocroticolimbic CREB and ERK signaling in C57BL/6J mice. J Neurochem 84: 1431-1441.

Center for Disease Control (2004). Cigarette smoking among adults-United States, 2002. Morbidity Mortality Wkly Rep 53: 428-431.

Collins AC, Luo Y, Selvaag S, Marks MJ (1994). Sensitivity to nicotine and brain nicotinic receptors are altered by chronic nicotine and mecamylamine infusion. J Pharmacol Experiment Therap 271: 125-133.

Collins AC, Marks MJ (1989). Chronic nicotine exposure and brain nicotinic receptors: influence of genetic factors. Prog Brain Res 79: $137-146$.

Collins AC, Romm E, Wehner JM (1988). Nicotine tolerance: an analysis of the time course of its development and loss in the rat. Psychopharmacology 96: 7-14.
Conners CK, Casat CD, Gualtieri CT, Weller E, Reader M, Reiss A et al (1996). Buproprion hydrochloride in attention deficit disorder with hyperactivity. J Am Acad Child Adol Psychiatr 35: 1314-1321.

Davis JA, Gould TJ (2006). The effects of DHBE and MLA on nicotine-induced enhancement of contextual fear conditioning. Psychopharmacology 184: 345-352.

Davis JA, James JR, Siegel SJ, Gould TJ (2005). Withdrawal from chronic nicotine administration impairs contextual fear conditioning in C57BL/6 mice. J Neurosci 25: 8708-8713.

Davis JA, Porter J, Gould TJ (2006). Nicotine enhances both foreground and background contextual fear conditioning. Neurosci Lett 394: 202-205.

Fanselow MS, Kim JJ, Yipp J, De Oca B (1994). Differential effects of the $N$-methyl-D-apartate antagonist DL-2-amino-5-phosphonovalerate on acquisition of fear of auditory and contextual cues. Behav Neurosci 108: 235-240.

Fiore MC, Bailey WC, Cohen SJ (2000). Treating Tobacco Use and Dependence. A Clinical Practice Guideline. US Department of Health and Human Services, Public Health Service: Rockville, MD.

Foulds J (2006). The neurobiological basis for partial agonist treatment of nicotine dependence: varenicline. Int J Clin Pract 60: $571-576$

Fu Y, Matta SG, Valentine JD, Sharp BM (1998). Desensitization and resensitization of norepinephrine release in the rat hippocampus with repeated nicotine administration. Neurosci Lett 241: 147-150.

Gould TJ (2003). Nicotine produces a within subject enhancement of contextual fear conditioning in C57BL/6 mice independent of sex. Integr Physiolog Behavr Sci 38: 124-132.

Gould TJ (2006). Nicotine and hippocampus-dependent learning: implications for addiction. Mol Neurobiol 34: 93-107.

Gould TJ, Feiro O, Moore D (2004). Nicotine enhances trace cued fear conditioning but not delay cued fear conditioning in C57BL/6 mice. Behav Brain Res 155: 167-173.

Gould TJ, Higgins JS (2003). Nicotine enhances contextual fear conditioning in C57BL/6J mice at 1 and 7 days post-training. Neurobiol Learn Mem 80: 147-157.

Gould TJ, Rukstalis M, Lewis MC (2005). Atomoxetine and nicotine enhance prepulse inhibition of acoustic startle in C57BL/6 mice. Neurosci Lett 377: 85-90.

Gould TJ, Wehner JM (1999). Nicotine enhancement of contextual fear conditioning. Behav Brain Res 102: 31-39.

Gould TJ, Lommock JA (2003). Nicotine enhances contextual fear conditioning and ameliorates ethanol-induced deficits in contextual fear conditioning. Behav Neurosci 117: 1276-1282.

Grilli M, Parodi M, Raiteri M, Marchi M (2005). Chronic nicotine differentially affects the function of nicotinic receptor subtypes regulating neurotransmitter release. J Neurochem 93: 1353-1360.

Hendricks PS, Ditre JW, Drobes D, Brandon TH (2006). The early time course of smoking withdrawal effects. Psychopharmacology (E-pub ahead print).

Henningfield JE, Keenan RM (1993). Nicotine delivery kinetics and abuse liability. J Counsulting Clin Psychol 61: 743-750.

Hughes JR, Gust SW, Skoog K, Keenan RM, Fenwick JW (1991). Symptoms of tobacco withdrawal. A replication and extension. Arch Gen Psychiatry 48: 52-59.

Hyman SE, Malenka RC (2001). Addiction and the brain: the neurobiology of compulsion and its persistence. Nat Rev 2: 695-703.

Jacobs I, Anderson DJ, Surowy CS, Puttfarcken PS (2002). Differential regulation of nicotine receptor-mediated neurotransmitter release following chronic (-)-nicotine administration. Neuropharmacology 43: 847-856.

Jarvis MJ (2004). Why people smoke. BMJ 328: 277-279.

Kenny PJ, Markou A (2001). Neurobiology of the nicotine withdrawal syndrome. Pharmacol, Biochem, Behav 70: 531-549. 
Kleinman KM, Vaughn RL, Christ S (1973). Effects of cigarette smoking and smoking deprivation on paired-associate learning of high and low meaningful nonsense syllables. Psychol Rep 32: 963-966.

Kratochvil CJ, Vaughan BS, Harrington MJ, Burke WJ (2003). Atomoxetine: a selective noradrenaline reuptake inhibitor for the treatment of attention-deficit/hyperactivity disorder. Exp Opin Pharmacother 4: 1165-1174.

Lambert NM, Hartsough CS (1998). Prospective study of tobacco smoking and substance dependence among samples of ADHD and non-ADHD participants. J Learn Disabil 31: 533-544.

Lerman C, Audrain J, Tercyak K, Hawk Jr LW, Bush A, CrystalMansour S et al (2001). Attention-deficit hyperactivity disorder (ADHD) symptoms and smoking patterns among participants in a smoking-cessation program. Nicotine Tobacco Res 3: 353-359.

Lerman C, Patterson F, Berretini W (2005). Treating tobacco dependence: state of the science and new directions. J Clin Oncol 23: 311-323.

Lin RZ, Chen J, Hu Z, Hoffman BB (1998). Phosphorylation of the cAMP response element-binding protein and activation of transcription by $\alpha 1$ adrenergic receptors. J Neurochem 273: 30033-30038.

Logue SF, Paylor R, Wehner JM (1997). Hippocampal lesions cause learning deficits in inbred mice in the Morris water maze and conditioned-fear task. Behav Neurosci 111: 104-113.

Marks MJ, Burch JB, Collins AC (1983). Effects of chronic nicotine infusion on tolerance development and nicotinic receptors. J Pharmacol Exp Therap 226: 817-825.

Marks MJ, Campbell SM, Romm E, Collins AC (1991). Genotype influences the development of tolerance to nicotine in the mouse. J Pharmacol Exp Therap 259: 392-402.

Marks MJ, Pauly JR, Gross SD, Deneris ES, Hermans-Borgmeyer I, Heinemann SF et al (1992). Nicotine binding and nicotinic receptor subunit RNA after chronic nicotine treatment. J Neurosci 12: 2765-2784.

Marks MJ, Stitzel JA, Collins AC (1985). Time course study of the effects of chronic nicotine infusion on drug response and brain receptors. J Pharmacol Exp Therap 235: 619-628.

Moran-Gates T, Zhang K, Baldessarini RJ, Tarazi FI (2005). Atomoxetine blocks motor hyperactivity in neonatal 6-hydroxydopamine-lesioned rats: implications for treatment of attention-deficit hyperactivity disorder. Int J Neuropsychopharmacol 8: 439-444.

Murchison CF, Zhang X, Zhang W, Ouyang M, Lee A, Thomas SA (2004). A distinct role for norepinephrine in memory retrieval. Cell 117: 131-143.

National Institute on Drug Abuse/National Institute of Health (2004). Research Report Series - Tobacco Addiction. http://www. drugabuse.gov/researchreports/nicotine/nicotine2.html\#addictive.

Nguyen HN, Rasmussen BA, Perry DC (2003). Subtype-selective up-regulation by chronic nicotine of high affinity nicotinic receptors in rat brain demonstrated by receptor autoradiography. J Pharmacol Exp Therap 307: 1090-1097.

Olale F, Gerzanich V, Kurytatov A, Wang F, Lindstrom J (1997). Chronic nicotine exposure differentially affects the function of human $\alpha 3, \alpha 4$, and $\alpha 7$ neuronal nicotinic receptor subtypes. J Pharmacol Exp Therap 283: 675-683.

Owen EH, Logue SF, Rasmussen DL, Wehner JM (1997). Assessment of learning by the Morris water task and fear conditioning in inbred mouse strains and F1 hybrids: implications of genetic background for single gene mutations and quantitative trait analyses. Neuroscience 80: 1087-1099.

Pandey SC, Roy A, Xu T, Mittal N (2001). Effects of protracted nicotine exposure and withdrawal on the expression and phosphorylation of the CREB gene transcription factor in rat brain. J Neurochem 77: 943-952.

Pauly JR, Marks MJ, Gross SD, Collins AC (1991). An autoradiographic analysis of cholinergic receptors in mouse brain after chronic nicotine treatment. J Pharmacol Exp Therap 258: 1127-1136.

Pauly JR, Marks MJ, Robinson SF, van de Kamp JL, Collins AC (1996). Chronic nicotine and mecamylamine treatment increase brain nicotinic receptor binding without changing $\alpha 4$ or $\beta 2$ mRNA levels. J Pharmacol Exp Therap 278: 361-369.

Peng X, Gerzanich V, Anand R, Wang F, Lindstron J (1997). Chronic nicotine treatment up-regulates $\alpha 3$ and $\alpha 7$ acetylcholine receptor subtypes expressed by the human neuroblastoma cell line SH-SY5Y. Mol Pharmacol 51: 776-784.

Peng X, Gerzanich V, Anand R, Whiting PJ, Lindstrom J (1994). Nicotine-induced in crease in neuronal nicotinic receptors results from a decrease in the rate of receptor turnover. J Pharmacol Exp Therap 46: 523-530.

Peng X, Katz M, Gerzanich V, Anand R, Lindstrom J (1993). Human $\alpha 7$ acetylcholine receptor: cloning of the $\alpha 7$ subunit from the SH-SY5Y cell line and determination of pharmacological properties of native receptors and functional $\alpha 7$ homomers expressed in Xenopus oocytes. Mol Pharmacol 45: 546-554.

Perry DC, Davila-Garcia MI, Stockmeier CA, Kellar KJ (1999). Increased nicotinic receptors in brains from smokers: membrane binding and autoradiography studies. J Pharmacol Exp Therap 289: $1545-1552$.

Phillips RG, Ledoux JE (1992). Differential contribution of amygdala and hippocampus to cued and contextual fear conditioning. Behav Neurosci 106: 274-285.

Picciotto MR, Corrigall WA (2002). Neuronal systems underlying behaviors related to nicotine addiction: neural circuits and molecular genetics. J Neurosci 22: 3338-3341.

Pluzarev O, Pandey SC (2004). Modulation of CREB expression and phosphorylation in the rat nucleus accumbens during nicotine exposure and withdrawal. J Neurosci Res 77: 884-891.

Pomerleau CS, Downey KK, Snedecor SM, Mehringer AM, Marks JL, Pomerleau OF (2003). Smoking patterns and abstinence effects in smokers with no ADHD, childhood ADHD, and adult ADHD symptomatology. Addict Behav 28: 1149-1157.

Rende R, Slomkowski C, McCaffery J, Lloyd-Richardson EE, Niaura R (2005). A twin-sibling study of tobacco use in adolescence: etiology of individual differences in extreme scores. Nicotine Tobacco Res 7: 413-419.

Rukstalis M, Jepson C, Patterson F, Lerman C (2005). Increases in hyperactive-impulsive symptoms predict relapse among smokers in nicotine replacement therapy. J Subs Abuse Treat 28: 297-304.

Singer S, Rossi S, Verzosa S, Hashim A, Lonow R, Cooper T et al (2004). Nicotine-induced changes in neurotransmitter levels in brain areas associated with cognitive function. Neurochem Res 29: 1779-1792.

Snyder FR, Davis FC, Henningfield JE (1989). The tobacco withdrawal syndrome: performance decrements assessed on a computerized test battery. Drug Alc Depend 23: 259-266.

Swanson CJ, Perry KW, Koch-Krueger S, Katner J, Svensson KA, Bymaster FP (2006). Effect of the attention deficit/hyperactivity disorder drug atomoxetine on extracellular concentrations of norepinephrine and dopamine in several brain regions of the rat. Neuropharmacology 50: 755-760.

Sweatt JD (2004). Mitogen-activated kinases in synaptic plasticity and memory. Curr Opin Neurobiol 14: 311-317.

Thomas MJ, Moody TD, Makhinson M, O’Dell TJ (1996). Activity dependent $\beta$-adrenergic modulation of low frequency stimulation induced LTP in the hippocampal CA1 region. Neuron 17: 475-482.

Thonberg H, Fredriksson JM, Nedergaard J, Cannon B (2002). A novel pathway for adrenergic stimulation of cAMP-responseelement-binding protein (CREB) phosphorylation: mediation via $\alpha 1$-adrenoceptors and protein kinase $\mathrm{C}$ activation. Biochem $\mathrm{J}$ 364: 73-79.

Tzavara ET, Bymaster FP, Overshiner CD, Davis RJ, Perry KW, Wolff $\mathrm{M}$ et al (2006). Procholinergic and memory enhancing 
properties of the selective norepinephrine uptake inhibitor atomoxetine. Mol Psychiatry 11: 187-195.

Warner C, Shoaib M (2005). How does bupropion work as a smoking cessation aid? Addicti Biol 10: 219-231.

Watabe AM, Zaki PA, O'Dell TJ (2000). Coactivation of $\beta$ adrenergic and cholinergic receptors enhances the induction of long-term portentiation and synergistically activates mitogenactivated protein kinase in the hippocampal CA1 region. J Neurosci 20: 5924-5931.

Watkins SS, Koob GF, Markou A (2000). Neural mechanisms underlying nicotine addiction: acute positive reinforcement and withdrawal. Nicotine Tobacco Res 2: 19-37.

Wehner JM, Keller JJ, Keller AB, Picciotto MR, Paylor R, Booker $\mathrm{TK}$ et al (2004). Role of neuronal nicotinic receptors in the effects of nicotine and ethanol on contextual fear conditioning. Neuroscience 129: 11-24.

Whiteaker P, Sharples CGV, Wonnacott S (1998). Agonist-induced up-regulation of á4â2 nicotinic acetylcholine receptors in M10 cells: pharmacological and spatial definition. Mol Pharmacol 53: 950-962.

Winder DG, Martin KC, Muzzio IA, Rohrer D, Chruscinski A, Kobilka B et al (1999). ERK plays a regulatory role in induction of LTP by theta frequency stimulation and its modulation by $\beta$-adrenergic receptors. Neuron 24: 715-726.

Wooltorton JR, Pidoplichko VI, Broide RS, Dani JA (2003). Differential desensitization and distribution of nicotinic acetylcholine receptor subtypes in midbrain dopamine areas. J Neurosci 23: 3176-3185. 